\title{
La cultura de masas y la actualidad del proyecto emancipador de la Escuela de Frankfurt
}

\author{
Luis Zúñiga Herazo ${ }^{1}$ \\ Universidad de Cartagena
}

\section{Resumen}

En este trabajo exponemos los aspectos más importantes de la crítica realizada por la Escuela de Frankfurt a la llamada "cultura de masas" característica de la sociedad capitalista tardía, e intentamos dilucidar las diferencias que otros análisis han descuidado entre cultura afirmativa y cultura de masas. La tesis central de nuestro trabajo es que el predominio actual de la cultura de masas, tanto en los llamados países desarrollados como subdesarrollados, mantiene vigente el proyecto emancipador de la primera generación de la Escuela de Frankfurt.

Palabras clave: cultura de masas, masa, individuo, estética placer desinteresado, emancipación.

\section{Abstract}

We present in this paper the most important aspects of the criticism made by Frankfurt School on the "mass cultures" like feature of the late capitalist society, and we try show the different than other analysis have forgot between affirmative culture and mass cultures. Hypothesis central of theme in our investigation reveal the dominant mass cultures of developed and undeveloped countries and emancipator project of first generation of Frankfurt School.

Key words: mass cultures, masses, individual, aesthetic, disinterested pleasure, emancipation.

\footnotetext{
${ }^{1}$ Magíster en Filosofía de la Universidad de los Andes. Docente del Programa de Filosofía de la Universidad de Cartagena y de la Universidad Tecnológica de Bolívar. e-mail: luisz1973@hotmail.com
}

Recibido: Marzo, 2010 - Aprobado: Junio, 2010. 
Desde Marx la teoría crítica se había desarrollado como teoría crítica de la sociedad capitalista; buscaba hacerse práctica y materializarse a través de la transformación del objeto de su crítica: la sociedad capitalista. No obstante, para que lateoría pudierarealizarse necesitaba de un sujeto social que la llevara a la praxis. Y ese sujeto, para Marx era el proletariado: el grupo histórico universal sobre el cual se sustentaba la producción del capitalismo y que estaba encargado de adquirir la conciencia necesaria para liderar el proceso de emancipación frente a los medios de dominio y control ideológico capitalistas.

El fracaso de la República de Weimar, la adopción de medidas cada vez más autoritarias en el régimen socialista en la antigua Unión Soviética, y el ascenso del fascismo y nazismo en Italia y Alemania, revelarían, sin embargo, lo distante que estaba la teoría de la práctica. Tales experiencias políticas mostraban un divorcio muy claro entre la teoría y los hombres que debían convertirla en praxis. Un grupo de intelectuales, conocido más tarde bajo el nombre de Escuela de Frankfurt, se propuso en este contexto una revisión minuciosa de los fundamentos de la teoría marxista, intentando explicar los errores cometidos durante la experiencia socialista y preparar lo que sería la acción futura. El desarrollo de los acontecimientos históricos posteriores determinaría en parte que sus vidas estuvieran más comprometidas con la reflexión académica que con la militancia política.

Para la llamada "primera generación" de la Escuela de Frankfurt, los análisis de los nuevos modos de dominación ideológicos desarrollados por el capitalismo tardío serían tan decisivos, que pronto se pudo advertir que sus estudios estaban más interesados en desenmascarar los mecanismos refinados e imperceptibles de dominación de la superestructura cultural que en el análisis de la base o infraestructura económica, incluso cuando el régimen nazi ya había abdicado. El psicoanálisis de Freud aportaría nuevos conceptos para ese análisis.

Este trabajo intenta mostrar, pues, que pese a que el análisis de la cultura de masas de la Escuela de Frankfurt se desarrolló en el marco de unas condiciones socio-históricas determinadas por el capitalismo fascista y la posguerra-condiciones que, ciertamente, han desaparecido en su mayoría en la época actual-, su teoría crítica de la cultura de masas y su propuesta emancipadora siguen conservando contenidos vigentes para pensar la emancipación de hoy.

\section{Sociedad industrial avanzada y cultura de masas}

Para el análisis de las diferencias entre cultura de masas y cultura afirmativa acudiremos a los estudios realizados por Theodor Adorno 
y Herbert Marcuse. El propósito es mostrar que, en comparación con la cultura afirmativa, la cultura de masas se vuelve mucho más funcional los procesos de integración del individuo con la sociedad capitalista. Procesos de integración que vienen caracterizados por una pérdida de la autonomía y la personalidad individual, una disminución de la crítica y de la capacidad de resistencia contra el sistema, así como la integración permanente de los sujetos que se opusieron al capitalismo en otras épocas.

Por "cultura de masas" entiende Adorno las diversas formas de producción y difusión en serie de los productos culturales que, desde la segunda mitad del siglo XX, se han convertido en objetos de consumo y productos de uso doméstico por los diversos sectores de la población de los países "desarrollados". Aunque en los siglos XVIII y XIX esos procesos de difusión de la cultura se habían dado a través de medios escritos como la prensa, los boletines, los folletos y los pasquines -siendo controlados, en general, por los grupos hegemónicos-, estos medios no tenían, en su distribución, la capacidad de alcanzar a todos los grupos de la sociedad. Desde finales del siglo XIX y comienzos del XX, los procesos de reproducción técnica incorporaron otros medios con mayores capacidades de difusión cultural como la radio y la televisión.

A pesar de la importancia otorgada por Marx al análisis de la base económica sobre los procesos de la superestructura cultural, en la ideología alemana había destacado la relevancia de los medios de reproducción de la cultura para el mantenimiento del control y el poder sobre la infraestructura económica de una clase dominante dada (Marx, 1993: 58). Ahora, más allá de que el control de los medios de comunicación fuese potestad de los grupos dominantes de la sociedad, no se puede desconocer su incidencia en los procesos de emancipación que tuvieron lugar en Europa y durante las luchas de independencia en América (siglos XVIII y XIX). Pues a través de los folletos y pasquines no sólo se divulgó gran parte de las ideas que sirvieron de estímulo a estos procesos revolucionarios, sino que también se configuraron los procedimientos y planes de acción que orientaban estas luchas ${ }^{2}$.

\footnotetext{
${ }^{2}$ Una idea más amplia en este sentido la encontramos en Guerra (1992), quien sostiene la tesis de que las luchas de independencia en América latina estuvieron orientadas, como las revoluciones en Europa, por la difusión de las ideas ilustradas. Estas últimas e difundieron más fácilmente tanto por la presencia de medios escritos, como los pasquines, los folletos, manuales y boletines, como por la aparición de ciertos espacios de sociabilidad entre los que destacaban los cafés y las tabernas.
} 
Habría que pensar sólo en la incidencia que tendría en las luchas de independencia la traducción de los Derechos Humanos (realizada por Antonio Nariño) y otros documentos escritos que sirivieron en su momento como conspiración contra los regímenes injustos. No resulta extraño por ello que el propio Kant sostuviera que para la ilustración la única condición requerida era el uso público de la propia razón -que era el uso "que alguien hace de ella en cuanto sabio ante la totalidad del público lector" (Kant, 1986: 33)-. Es decir, Kant consideraba indispensable para que un hombre pudiera hacer uso de su propio entendimiento que tuviera la libertad de expresar sus puntos de vistas sobre temas de interés para toda una comunidad, y por ende, que tuviera simultáneamente acceso a las reflexiones producidas por sabios en otros temas.

Entonces se tenía la plena confianza de que con los libros, las lecturas de periódicos, revistas, y acceso en general a la información, se crearían las condiciones que posibilitarían la emancipación y liberación de los regímenes despóticos y autoritarios. En Dialéctica del Iluminismo, Adorno y Horkheimer se refieren no sólo a la forma cómo la ciencia y la técnica ${ }^{3}$ terminarían cumpliendo unos propósitos diferentes a aquellos para los que habían sido creadas, sino también la forma cómo los periódicos, revistas y folletines ya no estaban orientados a contribuir a un proceso de ilustración. Para Adorno y Horkheimer era claro que en el siglo XX la información divulgada a través de estos medios no contribuía, por un lado, a derrumbar los mitos y falsas creencias, ${ }^{4}$ y por otro, tampoco ayudaban a la formación

${ }^{3}$ El pensamiento filosófico de la Ilustración confiaba plenamente que el dominio de la ciencia y la técnica liberaría a los hombres de las ilusiones, los mitos y los fantasmas, haciendo más libres tanto sus relaciones como seres genéricos, como sus relaciones con la naturaleza. Sin embargo, como este dominio y control sobre la naturaleza estaba basado principalmente en el trabajo humano, las disposiciones metódicas de la ciencia y la técnica terminaron ciertamente quitándoles el poder divino y misterioso a los fenómenos naturales, pero al costo de ejercer, por medio del trabajo, un dominio sobre la mayoría de los hombres. Así, pues, aquellas disposiciones técnicas no sólo penetraron en la naturaleza, sino también en todas las dimensiones de la existencia humana. En últimas, con la Ilustración el hombre logró despojarse de los mitos religiosos, pero sobre la base de construir un nuevo mito, esto es, la creencia de que los progresos de la ciencia y la técnica conducirían a los hombres a desarrollar una vida dentro de una sociedad más racional. Para una ampliación de esta tesis, véase Horkheimer y Adorno (1969).

${ }^{4}$ Adorno advertía nuevas formas de superstición y difusión del pensamiento irracional en las "páginas sociales" de los periódicos, referidas a temas ligeros como los horóscopos, las cartas astrales y los libros de superación personal. Esta metafísica popular estaba dirigida, paradójicamente, a un público de clase media que había tenido acceso al conocimiento y que "sabe como es el mundo". Para una ampliación del tema, véase Adorno (1972). 
de un pensamiento crítico y autónomo. Más bien la producción y distribución en masa de revistas, periódicos y libros, actuaba en contra de la capacidad del individuo de construir un proceso de reflexión y análisis que no estuviera ya determinado previamente por aquellos medios de formación de la opinión al servicio de los intereses de los grupos sociales dominantes.

Hemos ya anotado que los medios de difusión característicos en el siglo XVIII y XIX estaban determinados por los textos escritos, determinando que su proceso de percepción fuera únicamente la lectura -inaccesible por ello a un público iletrado-. En la medida en que estos medios escritos son sustituidos por otros como la televisión, que reemplaza el discurso escrito por el oral y la capacidad de representación mental de lo leído por el contenido explicito de las imágenes, logran penetrar incluso sobre aquel público que aun se sustraía de la lectura de la prensa y las revistas. No parece posible, por lo mismo, que los individuos en la época actual puedan escapar a su poder, ni siquiera en los países "subdesarrollados" donde estos bienes tienden a disminuir cada vez más sus costos.

Adorno sostenía que la radio, la televisión y la prensa estaban articuladas con la totalidad del sistema capitalista, al punto de considerarla (junto con el cine) integradas en lo que denominaba "industrias culturales". Para Adorno (1967: 35), la dependencia recíproca entre dicha industria cultural y otras formas de industrias como la textil, petrolera, energética y de servicios públicos ${ }^{5}$, hacía que en la sociedad industrial avanzada ya no se pudiera presentar a la superestructura cultural como una esfera separada de la infraestructura económica. Pues si bien los objetivos principales de las industrias culturales podían trascender al lucro -las ganancias y el interés que acompañan a las actividades productivas de otras industrias- configuraban toda una estructura técnica por medio de la cual los grupos dominantes difundían y reproducían sus valores e ideales sin que se vieran trastocados o amenazados por el público.

Tal ganancia, interés y lucro podían quedar subordinados a la ideología difundida desde la industria cultural, porque las capacidades del sistema eran (o son) de tal magnitud que era posible gastar gran cantidad de recursos en publicidad, y producir bienes y servicios im-

\footnotetext{
${ }^{5}$ La televisión, la radio y la Internet se convierten en las mediaciones entre lo que la industria capitalista produce y aquello que supuestamente los consumidores demandan. En esa mediación los medios de comunicación estimulan, promueven e imponen, a través de la publicidad, hábitos de consumo. Las ganancias alcanzadas obtenidas con esa publicidad no dejan duda de la dependencia recíproca entre esta y otras industrias.
} 
productivos, derroche planificado y obsolescencias. Para Adorno, el hiperconsumo de información en las sociedades actuales sería, bajo esta dialéctrica de la ilustración, contrario a los procesos de emancipación, actitud analítica y reflexiva de los individuos. Consideraba que el desarrollo del pensamiento autónomo dependía, paradójicamente, de la posibilidad de que el individuo pudiera tener un mayor tiempo libre alejado de dichos medios de comunicación.

Este análisis de Adorno también es compartido por Marcuse y los otros miembros de la primera generación de la Escuela de Frankfurt. Marcuse afirma quela sola idea de que el individuo pudiera contenerse a su deseo de estar informado y entretenido es considerada en sí misma como una idea de liberación catastrófica, pues la radio, la prensa, y sobre todo la televisión, se han convertidos en necesidades humanas de una importancia sólo comparable con las necesidades orgánicas. Marcuse anota:

\begin{abstract}
La mera supresión de todo tipo de anuncios y adoctrinamiento de información y diversión sumergiría al individuo en un vacío traumático en el que tendría la oportunidad de sorprenderse y pensar, de conocerse a sí mismo y a su sociedad. [...] Sin duda tal situación sería una pesadilla intolerable. Aunque la gente puede soportar la continua creación de armas nucleares, de lluvias radioactivas y comidas dudosas (por esta misma razón) no puede tolerar que se le prive de las diversiones y la educación que los hacen capaces para reproducir las disposiciones para su defensa o su destrucción (1993: 124).
\end{abstract}

La importancia de los medios de comunicación masiva en los individuos reflejaría así cierto grado de irracionalidad, en tanto a ellos les parecería más fácil acostumbrarse a la violencia que disminuir, por ejemplo, el tiempo que dispone cuando escucha y observa tales medios. En contraste con los planteamientos de la primera generación de la Escuela de Frankfurt, Habermas asumirá una posición más bien optimista frente a las contribuciones de los medios en los procesos de democratización de la sociedad. Habermas cree que gracias a los medios los ciudadanos pueden ejercer un mayor control sobre la gestiones de sus gobernantes y del Estado en general. Tanto quienes viven en un ámbito urbano como en uno rural tienen un mayor conocimiento sobre los derechos que las constituciones de sus países contemplan y los procedimientos para hacerlos cumplir. Así mismo, con unos costos económicos muy bajos, los medios contribuyen a 
la educación, formación cultural y entretenimiento de las personas, siendo asequibles a todo público.

Al respecto, debemos reconocer que no se puede negar la influencia que, eventualmente, tienen los medios como potencial de crítica de la sociedad. De alguna forma, Adorno lo reconocía en los medios escritos que existieron en los siglos XVIII y XIX, pero más difícil es aceptar que los medios en sí mismos cumplan este propósito atribuído por Habermas en una "sociedad democrática". Aunque un análisis más amplio del tema ${ }^{6}$ se encuentra fuera de los alcances de este trabajo, podemos afirmar que hoy se mantiene (y probablemente se ha incrementado) el poder de seducción ejercido sobre los individuos por proliferación de nuevos aparatos de comunicación. En países como Colombia, donde se está muy lejos de un desarrollo de la ciencia y la técnica, y donde prevalecen condiciones muy precarias en obras de infraestructura (carreteras, puentes y sistemas de servicios públicos), las telecomunicaciones avanzan a un nivel de desarrollo claramente contrastante con la gratificación de otras necesidades.

Así como el mayor consumo de medios no garantiza la ilustración de las personas, tampoco su acceso masivo es señal necesaria de mejores niveles de bienestar, pues más allá de la facilidad con que los bienes culturales son adquiridos por las masas en sociedades "no desarrolladas", es claro que las desigualdades sociales y económicas no sólo persisten, sino que incluso se han agudizado. La masificación de los productos culturales no puede entenderse, por esto, como un proceso de igualación social de los hombres, sino más bien como forma en que diversos grupos sociales pueden ser igualmente sometidos a las mismas formas de control y dominio por la sociedad respectiva.

\section{Cultura afirmativa y cultura de masas}

La "cultura de masas" que caracteriza a la cultura hegemónica de la sociedad capitalista tardía había estado precedida por lo que Marcuse denominó "cultura afirmativa". Esta había caracterizado a la sociedad burguesa durante los siglos XVIII y XIX, distinguiéndose por ser una cultura esencialmente idealista. En ella los valores estéticos, éticos y religiosos que conformaban el ámbito espiritual humano se realizaban sólo en las dimensiones internas del alma y de la interioridad humana, o bien se mantenían como anhelos y aspiraciones sólo posibles más allá de la vida en este mundo. Esta

${ }^{6}$ Podemos encontrar un análisis crítico del optimismo de Habermas frente a la función de democratización de los medios en Blesa (2006). 
cultura afirmativa separaba los ideales del arte, la filosofía y la religión de la esfera del trabajo y los negocios, y en esa separación los ideales se preservaban como expresiones humanas más elevadas y dignas de los hombres y como parte de un orden diferente al de los negocios y el trabajo.

Si bien Marcuse considera que esta cultura afirmativa predominó en la sociedad burguesa de los siglos XVIII y XIX ${ }^{7}$, no olvida que su origen teórico procede de los propios clásicos de la filosofía griega, quienes deslindaron radicalmente el ámbito de lo necesario y funcional (asociado al mundo del esfuerzo y sacrificio del trabajo) de la esfera de lo bello y verdadero (asociada al mundo del arte, la ciencia y la filosofía). Al defender la especialización de las funciones dentro de la organización del Estado y la sociedad, Platón y Aristóteles consideraron necesario separar el trabajo teórico de las labores prácticas asociadas a las necesidades de los habitantes de la polis. En esta concepción aristocrática de la cultura se encontraba implícita la idea de que aquellos que se dedicaban a una vida esfuerzo y fatiga, sin satisfacer nunca por completo sus necesidades, no podían alcanzar el reino de lo verdadero, el bien y la belleza.

El mundo burgués, para Marcuse, mantuvo la idea de que la cultura estaba asociada a las verdades más elevadas del ser humano, estableciendo sin embargo una diferencia con la Antigüedad: el gozo de la cultura no podía ser ahora sólo para una minoría privilegiada. Todos los hombres -independientemente de sus condiciones de vida material y del trabajo que realizaran- podían contemplar y gozar del reino de lo verdadero, el bien y la belleza (113). En la práctica, por supuesto, tal universalización de la cultura se convirtió, durante los siglos XVIII y XIX, en un simple ideal abstracto para las grandes masas que, como en otras épocas, se mantuvo ajena al acceso y gozo de los bienes culturales.

Aunque este carácter abstracto e idealista que tenía el gozo de la cultura en la sociedad burguesa no había cambiado en lo esencial desde el mundo antiguo, lo cierto es que Marcuse consideraba

\footnotetext{
${ }^{7}$ Tanto en los trabajos de Alicia Entel como de Blanca Muñoz (2000) se descuida esa diferencia en su origen histórico entre la cultura afirmativa y cultura de masas. En ese descuido no se distingue que la cultura afirmativa era la forma característica de la cultura burguesa de los siglos XVIII y XIX y que la cultura de masas es la forma característica de la cultura en la sociedad capitalista desde la segunda mitad del siglo XX. En la medida en que la primera generación de la Escuela de Frankfurt ha desarrollado su análisis en este último siglo sus estudios culturales se podrían decir incluso han estado más relacionados con el análisis de la cultura de masas que con el de la cultura afirmativa.
} 
comprensible que, bajo las condiciones de inmadurez material y técnica de aquellas épocas, el individuo no pudiera sujetar su felicidad a algo que escapara a su control y dominio, y que no fuese producto en ese momento del trabajo y del pensamiento humano. La ausencia de progreso técnico hacía que la escasa riqueza material existente dependiera todavía de situaciones imprevisibles. Por el contrario, en el mundo burgués -donde, gracias a el progreso técnico y consecuente desarrollo de la industria, se produjo una riqueza material sin precedente histórico-, esta noción abstracta de la felicidad encubría una situación fáctica: si bien habían cesado formalmente los privilegios y distinciones sociales existentes en la sociedad antigua para acceder a los bienes de la cultura, no habían desaparecido las causas que determinaron las diferencias reales -aquellas que hacen que sólo una minoría pueda disfrutar de los bienes producidos en una sociedad-.

Ahora bien, si esta separación realizada por la cultura afirmativa burguesa entre la vida espiritual y la vida material servía para preservar un orden social injusto (que permanecía intacto ante la belleza del arte, las verdades de la filosofía y la promesa de la felicidad en una vida más allá de este mundo), en sus elementos idealistas y trascendentes prevalecía todavía la idea de unos elementos que no habían sido integrados a la sociedad capitalista: la idea de un mundo que era, en su esencia, cualitativamente distinto. De ahí que Marcuse prefiera el carácter abstracto y trascendente de esta cultura afirmativa a la aparente concreción alcanzada por los valores culturales -y sus ideales como la belleza y la felicidad- en la cultura de masas.

En últimas, podría decirse que lo prevalente en los dominios de la cultura afirmativa es el conflicto entre lo que es y lo que debería ser, independiente de que, al trasladarse el debería ser a otro mundo, termine por aceptarse en la práctica lo que es. Dentro de la cultura de masas desaparece la diferencia entre lo espiritual y lo material, lo que es y lo que debería ser, al reconciliarse y armonizarse aparentemente el orden de la cultura con el orden de los negocios y el trabajo. En esta aparente reconciliación se debilita otra dimensión en la que el individuo podía manifestar su negación a la sociedad capitalista.

Dos diferencias debemos resaltar, entonces, entre la cultura afirmativa y la cultura de masas. La primera corresponde a que la separación realizada entre vida espiritual y realidad material al interior de la cultura afirmativa permitía que otras dimensiones de la vida humana, como el arte, la política y la religión, quedaran distantes de la lógica de los negocios y el comercio. En la cultura de masas, por el contrario, se disuelven esas diferencias al quedar sometidas estas 
dimensiones de la vida humana a los dominios del interés y el lucro. La segunda diferencia radica en que, mientras la cultura afirmativa contribuía con sus concepciones idealistas de la felicidad, la belleza, el bien y la justicia a trascender, teóricamente, las tensiones y contradicciones de la infraestructura económica capitalista, la cultura de masas pretende integrar los anteriores ideales como bienes más de intercambio económico ${ }^{8}$. En esa integración se erosionan los ideales y las diversas esferas sociales que los defienden: los partidos políticos, la familia, la religión y la escuela.

Hasta aquí hemos sostenido que, en teoría, una de las características de la cultura afirmativa era el carácter universalista que adquiría tanto la producción como el gozo de la cultura. En la cultura de masas, en cambio, señalábamos la forma cómo esta producción -pero sobre todo, el gozo de los bienes por las grandes masas- se había convertido en una posibilidad real en los países "desarrollados". El carácter más real de la universalidad de esta cultura de masas, sin embargo, no indica que tengamos hoy más sociedad. El consumo masivo de televisión, radio, telefonía celular e Internet, la asistencia a escenarios deportivos, conciertos y centros comerciales, no han ampliado el tejido social. Por el contrario, la afluencia de todas las industrias culturales que aparecen ahora como las nuevas formas de identificación entre los hombres (como las nuevas formas de sociabilidad en la sociedad contemporána ${ }^{9}$ ) , es causa y consecuencia del deterioro aun mayor de formas de sociabilidad como los partidos políticos, la familia, el trabajo, la escuela y las propias tradiciones y costumbres de los habitantes que hacen parte de un mismo contexto histórico-social.

Esta forma de "identificación" que crea el consumo se encuentra cimentada, en realidad, sobre bases que son muy débiles, en nada comparables con anteriores formas de identificación, como la clase y la militancia política, o formas de sociabilidad que resisten a ser

\footnotetext{
${ }^{8}$ En teoría, para algunos, y en la práctica, para otros, el mercado capitalista de la sociedad contemporánea puede vender: buena calidad de vida, asociada a las comodidades de un lujoso apartamento, vehículo, áreas deportivas, espacios de recreación, y oportunidades para estudiar, prolongar la vida y la juventud más allá de lo que la fantasía podía imaginar, gozar de unas vacaciones en lugares más desconocidos y exóticos, etc.

${ }^{9}$ Por "formas de sociabilidad" entendemos aquí las maneras en las que se establecen vínculos, lazos e identidades entre los seres humanos. Estas sociabilidades, ciertamente, no se reducen a relaciones de intercambio, pero a menudo son amenazadas a quedar convertidas en simples relaciones de interés bajo la lógica de acumulación de capital y en los procesos de explotación del trabajo y de cosificación de las diversas esferas de la vida social.
} 
integradas y homogenizadas culturalmente, como las minorías étnicas. Es preciso aclarar, no obstante, que la crítica realizada por Adorno y Marcuse a la cultura de masas no significa una supuesta actitud de defensa de los miembros de la Escuela de Frankfurt a favor de una cultura elitista, o de cierta concepción despectiva frente a lo que representan los hombres que se hallan reunidos en masa. No hay nada que, a este respecto, pueda acercar Adorno con el pensamiento de autores como Ortega y Gasset (1970) -quien veía en la masa la decadencia y disolución de los valores más elevados de la civilización-. Por el contrario, Adorno nos advierte que en este desprecio a las masas claramente se ocultan intenciones ideológicas que, en vez de ayudar a descubrir las causas por las que la demagogia de los regímenes autoritarios pueden cohesionar y manipular a una multitud de hombres, sirve como pretexto para que los hombres agrupados en masa sean objeto de controles (Adorno \& Horkheimer, 1969: 88).

Debemos, pues, deslindar la crítica que Adorno realiza a la cultura de masas de una supuesta actitud de desprecio, como se podría inferir del supuesto elitismo cultural que se le adjudica, incluso por biógrafos de la Escuela de Frankfurt como Martin Jay (1974). Aunque Marcuse y Adorno prefirieran la cultura afirmativa a la cultura de masas y la noción idealista a la falsa concreción de los valores culturales en la cultura materialista, tienen claro que la cultura burguesa del siglo XIX conservaba sólo los ideales en un mundo abstracto y trascendente. Autores como Martín Barbero (1998: 51-71) se equivocan cuando acusan a Adorno de construir una valoración negativa de lo que significa la vida de los hombres que se agrupan dentro de una masa. En esto permanecería Adorno fiel al pensamiento de Marx, quien seguramente idealizó por sus mismas circunstancias históricas el potencial revolucionario de la masa obrera.

Los procesos de integración del individuo a la cultura de la sociedad capitalista indican que la eficiencia de los procesos de control y manipulación no está sujeta a la incorporación del individuo a una masa, o agrupación. La misma noción de "cultura de masas" puede resultar equívoca si se toma sólo como la difusión de la actividad cultural en espacios masivos o colectivos. La televisión, la radio y la Internet prueban que los medios masivos pueden difundir su publicidad en espacios privados, pero conservando su carácter accesible a las masas. A la inmediatez del tiempo, le corresponde la cercanía en que se hallan los individuos dentro de la cultura de masas en espacios como los que ofrecen los centros comerciales y los sistemas de transporte masivo de todo el mundo. Esa cercanía no es, sin embargo, muestra de que estemos más cohesionados 
socialmente, puesto que nunca antes estuvimos tan atomizados y dispersos como individuos.

En este sentido, la crisis de representación en nuestras sociedades y las limitaciones de los referentes que constituyen identidad y crean comunidad, como la religión, los partidos políticos y las organizaciones sociales, en vez de acabar con la cultura de masas terminan fortaleciéndola, pues pareciera que el propio consumo fuera ahora el reemplazo para esas identidades y elementos de sociabilidad. Por lo demás, la misma sociabilidad tendría unas mayores posibilidades de universalización con las capacidades de comunicación ofrecidas por la Internet y la telefonía celular. Posibilidad que, en el caso de mayoría de las llamadas redes sociales en la Internet, se manifiesta principalmente a través del carácter frívolo y banal de sus contenidos.

\section{La redefinición de la emancipación en términos de una nueva antropología}

El propósito de este apartado es mostrar que no es acertada las objeciones de pesimismo que algunos atribuyen al análisis de Marcuse sobre la sociedad industrial avanzada ${ }^{10}$. Al contrario, nuestra idea es que Marcuse fue bastante optimista, a pesar del agudo análisis que hizo de las formas de control y dominación ejercidas por la sociedad avanzada sobre el individuo. Tan optimista, que hoy podríamos problematizar algunas de las expectativas que tenía en lo que llamaba "las fuerzas subjetivas del cambio social". Tal noción, tomada por Marcuse de la dialéctica hegeliana, suponía que en la sociedad capitalista avanzada existían las condiciones técnicas e intelectuales para que los cambios pudieran pasar de la cantidad a la cualidad. Esto es, del incremento del tiempo de ocio a la realización del tiempo libre; de la disminución del tiempo de la jornada de trabajo a la abolición del trabajo enajenado, y de la producción y distribución masiva de toda clase de bienes y servicios a la superación del hambre y la miseria en el mundo.

\footnotetext{
${ }^{10}$ Dubiel (2000) afirma que la perspectiva crítica del observador no participante de un proceso de dominación, es necesaria explicarla, pues de que forma seria posible una teoría crítica frente a una sociedad donde hay un dominio total. La respuesta a esa inquietud está presente en la teoría de Marcuse que considera que no se puede medir el nivel de control y dominio que ejerce la sociedad sobre el individuo común por el nivel de emancipación en que se encuentran ciertos individuos, así como no se puede determinar la conciencia crítica de un sociedad determinada por las reflexiones que se realiza en las instituciones académicas. Para una ampliación de las críticas realizadas por Dubiel a la primera generación de la escuela de Frankfurt, ver Dubiel (2000).
} 
Desde luego que Marcuse creía que la realización de esta posibilidad implicaba la aparición de una organización social incompatible con las formas de acumulación de capital y explotación del trabajo asalariado en los países capitalistas y las formas coloniales y neocoloniales de explotación de los recursos naturales por parte de los países "desarrollados" sobre los países "subdesarrollados" o del "tercer mundo". Pero la realización de esta posibilidad resultaba especialmente incongruente con la actual organización del aparato tecnológico de capitalismo tardío, dispuesto a la creación, por un lado, de obsolescencias, derroche planificado, publicidad y falsas necesidades, y por otro, orientado a la industria armamentista.

Ahora bien, Marcuse estaba seguro de que la sociedad industrial avanzada tenía ya maduras las condiciones objetivas, en el sentido de contar con todos los recursos técnicos e intelectuales disponibles, para realizar tal cambio cualitativo. Ese camino lo encontraba en la automatización, definida como el proceso a través del cual el trabajo físico necesario se sustraía cada vez más del proceso material de producción. Dentro de ella la fuerza de trabajo humano, su sacrificio, su esfuerzo y entrega, parecían ser cada vez menos importantes frente a las propias capacidades de la tecnología, pues era el nivel de desarrollo de esta última, y no el trabajo del hombre, lo que permitiría determinar el mayor o menor rendimiento de la producción. Para Marcuse lo que estaba en juego era la compatibilidad del progreso técnico con las propias instituciones bajo las que se había desarrollado la industrialización.

Marcuse alude a una crisis en la moral puritana del trabajo, en la ética del rendimiento y en el principio del éxito. Y uno puede advertir, ciertamente, que los procesos de racionalización del trabajo (en el sentido de un cálculo cada vez más exacto en el resultado del proceso productivo ${ }^{11}$ ) minimizaban la importancia de estos valores, tanto en el trabajo del obrero como del empresario. También es evidente la forma cómo la tecnología produce una revolución cultural al erosionar los procesos de socialización tradicional que habían caracterizado las relaciones de la familia burguesa en la que los adultos saben cada vez menos frente a los niños que se adaptan y aprenden a manipular más rápidamente los nuevos aparatos, ya sea de juegos de video u otros aparatos eléctricos. La pregunta, sin embargo, es si la automatización por sí misma produce un cambio cualitativo.

${ }^{11}$ Esta forma de entender la racionalización en el trabajo es desarrollada por Lukács (1986). 
Al respecto, Catalina Rojas y José Taberner consideran que las esperanzas depositadas por Marcuse en el progreso técnico han resultado ser demasiado optimistas. Con el tiempo, afirman:

Hemos visto asumir al capitalismo sin frenos la automatización, acelerando a su favor, millones de empleados son despedidos en Europa y se los mantiene unidos al cordón umbilical con la esperanza de que si hay paz aumentaran los puestos de trabajo. [...] La automatización aumenta y la determinación colectiva de la producción no se aproxima por estos lugares (1984: 148).

Es preciso señalar que Marcuse era consciente de que, para convertirse en una nueva fuerza de cambio, la automatización debía está precedida de una nueva organización de la técnica, de nuevas prioridades en su producción, pero también de la aparición de una conciencia individual que se hubiera emancipado de la sociedad de consumo. Marcuse anota:

Para que las posibilidades técnicas no se conviertan en
posibilidades de la represión, para que puedan cumplir su
función liberadora y pacificadora, tienen que ser sostenidas
y conquistadas por necesidades liberadoras y pacificadoras
[...] Cuando no existe la necesidad vital de que se suprima
el trabajo, cuando por el contrario, existe la necesidad de
continuación del trabajo hasta cuando este deje de ser feliz
con la conciencia tranquila, sino la necesidad de tener que
ganarlo y merecerlo todo, en una vida que es todo lo miserable
que se pueda imaginar, cuando esas necesidades no existen
o existiendo son apagadas por las necesidades represivas
entonces, lo único que se puede esperar de las nuevas
posibilidades técnicas es que se conviertan efectivamente en
posibilidades de la represión (1995: 14).

Es decir, para que la automatización, como condición objetiva, pudiera contribuir al cambio cualitativo se requeriría no sólo de una nueva orientación en la producción, sino también de una transformación de las condiciones subjetivas. Ahora bien, uno de los cambios que trajo consigo la incorporación de la automatización en los procesos productivos fue la sustitución cada vez mayor del obrero por los nuevos operarios de las máquinas: técnicos, ingenieros y supervisores. Estos, por su condición de bien remunerados y satisfechos del sistema, no podían sustituir el poder histórico de 
transformación social que los iniciadores de la teoría crítica (MarxEngels) habían atribuido a los obreros ${ }^{12}$.

Aunque Marcuse reconocía que la ausencia de un sujeto que llevara a su concreción la teoría no implicaba que el obrero pudiera ser sustituido por otros grupos de la población, como los estudiantes, las minorías étnicas, los movimientos feministas y ecológicos ${ }^{13}$, confiaba en lo que podrían representar éstos como fuerzas opuestas al sistema capitalista. Esa confianza fue fortalecida por lo que podía percibir Marcuse, especialmente del movimiento estudiantil en la década de los sesenta (movimiento cuya máxima expresión política fue alcanza en el mayo parisino del 68). Cuatro décadas después nos corresponde analizar qué tan válida era esa confianza depositada por Marcuse en el movimiento estudiantil y en los llamados grupos infraprivilegiados.

En ese orden, tenemos que tanto Marcuse como Habermas consideraban que los estudiantes hacían parte de los grupos privilegiados, pues provenían la mayoría de estratos sociales y económicamente favorecidos. Es decir, de hogares donde regularmente habían sido satisfechas las necesidades más elementales y donde habían sido superadas las angustias por sobrevivir. Esto hacia que los motivos de su protesta no provinieran de un reclamo de mayores compensaciones. Así mismo, el ambiente de comprensión en que habían sido educados -bajo principios más bien liberales- determinaba que el origen de su protesta tampoco se pudiera presentar como el tradicional conflicto de la familia burguesa. El motivo de las protestas de los estudiantes se dirigía, más bien, contra el propio sistema de compensaciones que por un reclamo de mayor participación en las compensaciones sociales disponibles, como son los ingresos y el tiempo de ocio (Habermas, 1978: 95).

Marcuse, quien compartía con Habermas el hecho de que la mayoría de los activistas estudiantiles se encontraba en una situación socio-económica ventajosa, sostenía que la oposición de los estudiantes era, en realidad, contra todo el modo de vida de la

\footnotetext{
${ }^{12}$ Mallet crítica a Marcuse, sosteniendo que so pretexto de que la clase obrera no percibe fácilmente la contradicción entre la liberación que ya es posible y el uso represivo que el capitalismo hace de los recursos de la técnica, Marcuse concluye algo apresuradamente que esta contradicción no es perceptible. Mallet, como muchos de los críticos de la época, se equivocaban probablemente al no conocer en su conjunto la obra de Marcuse. Para una ampliación de esas críticas, véase Mallet (1970).

${ }^{13}$ Estos grupos, para Marcuse, podían actuar como catalizadores en el proceso de transformación social, pero no eran de ningún modo los nuevos sujetos de la revolución. Para una idea más amplia, cf. Marcuse (1986: 53-62).
} 
sociedad opulenta: contra la sociedad de consumo, la guerra y la disciplina del trabajo alienado. Una valoración de los potenciales de transformación de las luchas de los movimientos estudiantiles no debe olvidar, sin embargo, que ellas se encuentran limitadas, primero, porque la condición de estudiantes es apenas para los jóvenes: una etapa transitoria de preparación para la inserción al mercado laboral; segundo, porque, como estudiantes los jóvenes, no tienen ningún poder material real que pueda amenazar el funcionamiento del sistema. No pueden paralizar las tecnologías, pues no la controlan. Y tercero, porque los estudiantes tampoco conforman una clase socialmente definible. La constancia de su oposición a la sociedad capitalista está sujeta, en gran forma, a la falta de oportunidades de empleo que genera la introducción de los procesos de automatización en la industria, tanto de los países "desarrollados" como de los "subdesarrollados".

No obstante, es este mismo incremento del desempleo provocado por los procesos de automatización el que contribuye a debilitar las fuerzas de oposición contra el sistema capitalista. Pues el denominado por Marx "ejercito laboral de reserva" ${ }^{14}$, o sector de la fuerza de trabajo inutilizada por el capital, constituye una fuente potencial a través de la cual el capitalismo puede sustituir una fuerza física y mental por otra. Dicho "ejército laboral", por su número y heterogeneidad, constituye un problema al momento en que la clase trabajadora amenace con retirarse de la actividad productiva. El asunto aquí es, pues, que si la oposición al sistema va a depender de los estudiantes, o de los profesionales cuando todavía no se han incorporado al mercado laboral, entonces las fuerzas que hacen oposición al sistema habrían de estar por fuera de la infraestructura económica.

Esto se torna más evidente cuando Marcuse valora el potencial de antagonismo que pueden tener los "infraprivilegiados". Así llama a las minorías raciales y a las minorías nacionales de las sociedades avanzadas, y en general, a la población desempleada y subempleada. Los infraprivilegiados existen fuera del proceso democrático; su vida es la necesidad inmediata y lo más real para poner fin a instituciones y condiciones intolerables. Su oposición es revolucionaria, incluso si su conciencia no lo es; su oposición golpea al sistema desde el exterior, y por tanto, no es derrotada por él: es una fuerza que viola las reglas del juego y, al hacerlo, lo revela como

\footnotetext{
${ }^{14}$ Este concepto fue utilizado por Marx, especialmente en los Manuscritos (1993) y en El Capital (1986) para referirse a la población trabajadora excluida del proceso de producción.
} 
partido trucado. Cuando se reúnen y salen a la calle sin normas y sin protección, para pedir los derechos civiles más primitivos, saben que tienen que enfrentarse a perros, piedras, bombas, cárcel, campos de concentración, incluso la muerte (Marcuse, 1986: 53). Marcuse confiaba entonces que el "lumpen proletariado", grupo social sobre el que Marx guardaba muchas reservas, pudiera convertirse en una fuerza que, desde el exterior, atacara al sistema. Es decir, desde su ubicación por fuera del proceso productivo y de la propia sociedad de consumo.

Habermas, en contra de esa confianza, consideraba que semejante ubicación por fuera de la actividad productiva era, justamente, lo que restaba posibilidades de éxito a su acción revolucionaria, pues el sistema no dependía de su esfuerzo para su cabal funcionamiento. Las posibilidades de sublevación de los infraprivilegiados se veían así reducidas por los propios términos en que Marcuse planteaba los motivos del cambio cualitativo de esta sociedad. Esto es, que para Marcuse la revolución no estallaría como respuesta a la pauperización económica, sino sobre la base de la emancipación de la sociedad de consumo. Y esto conllevaría a una inconsistencia, en la medida en que los infraprivilegiados no constituían, en realidad, un potencial de la sociedad consumidora. Por el contrario, la sociedad de consumo sería una sociedad de privilegiados, que explotaba o explota (de forma abusiva) los recursos naturales del mundo, consumiéndolos sin ningún tipo de control. Estados Unidos tenía, por ejemplo (en la época en que Marcuse analizaba a la sociedad industrial avanzada), aproximadamente el $6 \%$ de la población mundial y consumía aproximadamente el 33\% de los recursos globales de energía, y en algunas materias primas, el $40 \%$.

La idea de que la revolución estallaría como respuesta a la crítica de la sociedad de consumo, y no sobre la base de la pauperización, resultaba bastante problemática si se esperaba que los infraprivilegiados pudieran rechazar aquellas cosas que nunca habían poseído y que probablemente desearían tener. De alguna manera, la pregunta sobre el sujeto encargado de realizar el cambio cualitativo no quedaba claramente definida en el pensamiento de Marcuse. Esa indefinición no respondía únicamente al hecho de que la teoría careciera de un agente histórico específico que pudiera llevarla a la praxis, sino también de la importancia que adquieren en la idea de cambio cualitativo los procesos de emancipación de la sociedad de consumo. En un ensayo titulado "La rebelión de los instintos vitales," Marcuse parece percatarse de las implicaciones de que el cambio cualitativo dependiera de una emancipación de la sociedad de consumo: 
Se trata de una protesta de todas las clases de la sociedad, motivada por una profunda incapacidad física y moral para hacer el juego y por la decisión de salvar lo que todavía puede salvarse de humano, de alegría y de autodeterminación: una rebelión de los instintos vitales contra los instintos de muerte organizados socialmente (1993: 71).

Es decir, en este ensayo Marcuse es más consistente con la idea de que si la sociedad de consumo había penetrado sobre las diversas clases sociales, entonces la emancipación contra ésta no podía ser sólo obra de una clase social determinada. La consecuencia es que la idea del cambio cualitativo en Marcuse parece tener, en últimas, más una dimensión de carácter antropológico que político. Marcuse mismo reconocía que esta preponderancia de la subjetividad podía ser interpretada como un movimiento englobante, aislado de las masas y con cierto carácter elitista, sin embargo pensaba que tal desconfianza podía desaparecer tan pronto se reconociera que el valor político de la subjetivización se hallaba en los valores de autodeterminación. Si esto es así, no obstante, la revolución de los instintos vitales tendrá un mayor compromiso con la emancipación que con la realización de una sociedad socialista. Y esto hace que Marcuse se encuentre tan cerca de Marx, como lo puede estar de otros filósofos modernos como Kant o Rousseau.

\section{La emancipación humana y la subjetivización estética}

La preocupación por una redefinición de la antropología del hombre contemporáneo se encuentra tanto en lo que Marcuse denomina "dimensión estética", como en la idea de un nuevo hombre. Marcuse sostiene que predomina en la conciencia del hombre contemporáneo la noción de que la dimensión estética pertenece a un ámbito esencialmente irreal. Esto, considera, es resultado de una represión cultural, y por ello le interesa deshacerla acudiendo al sentido original y a la función de la estética. El filósofo y sociólogo aleman se interesa principalmente en los aspectos más importantes de las estéticas de Kant y Schiller, e infiere de ellas la posibilidad de una revolución en las formas de percepción y relación sensible con la naturaleza.

En la filosofía de Kant, efectivamente, se pretende una mediación entre el mundo fenoménico (del cual se ocupa la razón teórica) y el mundo nouménico (cuyas ideas sirven como ideas regulativas y como presupuesto). Kant anotaba que una de las características principales del juicio del gusto era que producía un placer desinteresado. Dicho desinterés implicaba que no importaba si existía o no el objeto, pues lo bello no estaba en el objeto como una propiedad objetiva, sino en 
el sentimiento subjetivo que resultaba de la forma como habíamos sido afectados por la representación del objeto. Para Kant (1992: 122) "interés" significaba la complacencia relacionada con la facultad de desear, que suponía querer que ese algo existiera. En cambio, el carácter imparcial del juicio del gusto implicaba que éste no debía estar en lo más mínimo predispuesto a favor de la existencia de la cosa, sino ser indiferente para poder juzgar (1992: 122).

Sea lo que sea el objeto (cosa, flor, animal u hombre) es representado y juzgado no en términos de su utilidad, ni en virtud de su finalidad interna, ni de acuerdo al propósito al que pueda servir. El objeto es representado, en la imaginación, libre de todas aquellas relaciones y propiedades. La experiencia estética es así diferente de la experiencia cotidiana y de la experiencia científica. Es fácil advertir cómo esta experiencia del juicio del gusto supone una relación con el mundo que nada tienen que ver con la forma como los hombres se relacionan con el mismo en una sociedad hiperconsumista. Esto es lo que Marcuse recupera de la estética de Kant: la posibilidad de que el sujeto y el objeto lleguen a ser libres en un nuevo sentido. Puesto que el esfuerzo de Kant por mediar en la dimensión estética la razón con la sensibilidad es el "intento de reconciliación de dos dimensiones de la existencia humana que habían sido separadas por la represión del principio de realidad" (Marcuse, 1983: 169).

Por su parte, Julián Marrades (1997) considera que se pueden encontrar en la filosofía de Schiller dos concepciones antropológicas. La primera identifica un dualismo originario entre la razón y la naturaleza, el carácter moral y el carácter natural del hombre. La segunda considera posible integrar armónicamente en unidad esas dos determinaciones de la existencia humana. La segunda tesis conforma, por supuesto, un ideal, pues se considera un proyecto que el hombre debe realizar en su existencia individual y social. La realización de ese proyecto exige una doble tarea. En la primera, el hombre transforma del mundo todo lo que es simple forma para dar realidad a todas sus disposiciones. La segunda requiere de absoluta formalidad, pues debe prescindir de todo lo que sea exclusivamente del mundo y otorgar armonía a todas sus variaciones. Para realizar las anteriores tareas el hombre dispone de dos impulsos: el impulso sensible y el impulso racional. De la armonía que resulta de esos dos impulsos surge un tercer carácter que representaría una idea de perfección humana y que estaría orientado por el impulso del juego (su desarrollo sólo sería posible a través de la educación de la sensibilidad y la razón) (Schiller, 1990). 
No obstante, en un mundo donde todo está prácticamente cosificado, incluyendo la educación, no se puede decir que habría personas que pudieran realizar esta tarea. Marcuse, sin embargo, retoma de la estética de Schiller el intento de armonía entre razón y sensibilidad. Armonía que considera fundamental en la configuración no sólo de un tipo de sociedad cualitativamente diferente, sino también de un nuevo hombre. Más allá del carácter especulativo, abstracto y utópico de la dimensión estética, es claro que constituye una posibilidad frente al hiperconsumo y cosificación en la cultura de masas. Desde luego que una sociedad que promueve el hiperconsumo en las masas, la praxis al menos individual de esta dimensión estética se convertiría en un potencial para la emancipación de la cultura de la sociedad capitalista.

\section{Bibliografía}

Adorno, T. (1972). Filosofía y superstición. Madrid: Taurus.

Adorno, T. \& Horkheimer, M. (1969). Dialéctica del Iluminismo. Buenos Aires: Sur.

cultural. Buenos Aires: Galerna.

(1967). "La industria Cultural". En La industria . (1969). La sociedad: lecciones de sociología.

Buenos Aires: Proteo.

Blesa, P. (2006). “Medios de comunicación y democracia: ¿el poder de los medios o los medios?", Revista Ciencias sociales de la comunicación, $\mathrm{n}^{\circ}$ 6, Murcia.

Dubiel, H. (2000). La teoría crítica ayer y hoy. México: Plaza y Valdez.

Entel, A. (2001). Acerca de la felicidad: un análisis de tres escritos de Herbert Marcuse. Buenos Aires: Prometeo.

Fredu, S. (1996). "Psicología de las masas y análisis del Yo". En Obras completas. Madrid: Biblioteca nueva, vol. III, pp. 2563-2610.

Friedman, G. (1986). La filosofía política de la escuela de Frankfurt. México: Fondo de Cultura Económica.

Guerra, F. (1992). Modernidad e independencia: ensayos sobre las revoluciones hispánicas. Madrid: Mapfre.

Habermas, J. (1978). Respuesta a Marcuse. Barcelona: Anagrama. . (2002). Ciencia y técnica como ideología. Madrid: Tecnos.

Jay, Martin. (1974). La imaginación dialéctica: una historia de la escuela de Frankfurt. Madrid: Taurus.

Jiménez, J. (2002). La estética como utopía antropológica: Bloch y Marcuse. Madrid: Tecnos.

Kant, E. (1986). "Respuesta a la pregunta: ¿Qué es la ilustración?", Argumentos, $\mathrm{n}^{\circ} 14-17$, Bogota. (1992). Crítica de la facultad de juzgar. Caracas: Monte Ávila.

Lukács, G. (1986). Historia y conciencia de clase. Buenos Aires: Orbis. Mallet, G. et. al. (1970). Marcuse ante sus críticos. México Grijalbo. 
Marcuse, H. (1983). Eros y civilización. Madrid: Sarpe.

- (1985). Contrarrevolución y revuelta. México: Joaquín Mortiz. . (1993). El hombre unidimensional. Barcelona: Planeta De Agostini.

. (1995). El final de la utopía y otros ensayos. México: Planeta De Agostini.

. (1967). "Acerca del carácter afirmativo de la cultura". En Cultura y sociedad. Buenos Aires: Sur.

. (1967). "Ensayo sobre la liberación". En Cultura y sociedad. Buenos Aires: Sur.

. (1986). "El problema de la violencia en la oposición". En El final de la utopía y otros ensayos. Bogotá: Planeta De Agostini.

- (1981). La agresividad en la sociedad industrial avanzada. Madrid: Alianza.

. (1993). "La rebelión de los instintos vitales", Ideas y Valores, Bogotá, Universidad Nacional de Colombia.

Marrades, J. (1997). "A partir de Schiller: naturaleza, juego y libertad". En Ensayos sobre necesidad y libertad. Valencia: Pretextos.

Martín-Barbero, J. (1998). De los medios a las mediaciones. Bogotá: Convenio Andrés Bello.

Marx, K. (1986). El capital. Barcelona: Orbis.

. (1994). La ideología alemana. Valencia: Universitat Valencia. - (1993). Manuscritos. Barcelona: Altaya.

Muñoz, B. (2000). Theodoro W. Adorno: teorìa crìtica y cultura de masas. Madrid: Fundamentos.

Ortega y Gasset, J. (1970). La rebelión de las masas. Madrid: Espasa-Calpe.

Rojas, C. \& Taberner, J. (1984). Marcuse, Fromm, Reich: el freudomarxismo. Madrid: Cincel.

Schiller, F. (1990). Kallias-Cartas de la educación estética del hombre. Barcelona: Anthropos. 
